\begin{tabular}{||c|c||c||}
\hline Received: Agustus 2018 & Accepted: Januari 2019 & Published: Januari 2019 \\
\hline \hline \multicolumn{2}{|c|}{ Article DOI: $\underline{\text { http://dx.doi.org/10.24903/jam.v3i1.360 }}$} \\
\hline \multicolumn{2}{|c|}{} \\
\hline \multicolumn{2}{|c|}{} \\
\hline
\end{tabular}

\title{
Peningkatan Produksi Tempe Daun Desa Loh Sumber Kecamatan Loa Kulu Kabupaten Kutai Kartanegara
}

\author{
Julianur \\ Universitas Muhammadiyah Kalimantan Timur \\ julianur@umkt.ac.id \\ Januar A.S \\ Universitas Muhammadiyah Kalimantan Timur \\ jas970@umkt.ac.id \\ Praja H.S \\ Universitas Muhammadiyah Kalimantan Timur \\ praja.hs@umkt.ac.id
}

\begin{abstract}
Abstrak
Desa Loh Sumber salah satu desa yang berada di Kecamatan Loa Kulu, Kabupaten Kutai Kartanegara yang merupakan salah satu desa yang memiliki produksi lokal berupa tempe daun dan kerupuk dimana pangan tersebut merupakan khas dari desa loh sumber. Kegiatan Iptek Kewirausahaan untuk Masyarakat (IKuM) ini, difokuskan pada usaha produksi tempe. Usaha yang sudah ada sekitar 16 tahun lalu ini merupakan bagian dari UMKM (usaha mikro, kecil dan menengah) masyarakat yang dikembangkan oleh individu atau suatu kelompok. Dalam mengembangkan UMKM tempe daun tersebut dibutuhkan kerja keras dan didukung oleh beberapa aspek seperti tenaga (karyawan) dan alat modern penunjang hasil produksi tempe, agar meningkatkan omset dan kesejahteraan masyarakat. Berbagai macam kendala tentu dirasakan oleh pelaku usaha dalam menjalani usaha tempe tersebut seperti tingginya permintaan masyarakat akan tempe daun yang berbanding terbalik dengan rendahnya jumlah produksi yang dihasilkan, akibatnya pelaku usaha belum bisa memenuhi kebutuhan masyarakat yang cukup tinggi karena masih menggunakan metode tradisional dalam pengolahan tempe yaitu menggiling kedelai secara manual. Tempe daun sangat bermanfaat bagi konsumen yaitu rasanya yang lebih nikmat dan lebih sehat karena menggunakan kemasan alami berupa daun pisang. Melihat dari kendala tersebut kami ingin memberikan sebuah solusi atau metode agar pelaku usaha mampu memenuhi kebutuhan masyarakat, penerapan teknologi modern seperti mesin pengupas kulit kedelai dan penambahan alat-alat pendukung lainnya seperti ember, baskom dan lainnya adalah solusi yang cukup efektif untuk meningkatkan jumlah produksi sekaligus meningkatkan kepercayaan masyarakat dalam mengkonsumsi tempe daun tersebut, tentu ini akan berdampak langsung pada meningkatnya omset bagi pelaku usaha.
\end{abstract}

Kata Kunci: Tempe daun, desa Loh Sumber 


\section{(A) ABDIMAS}

https://journal.uwgm.ac.id/index.php/abdimasmahakam/index

E-ISSN: 2549-5755

Januari 2019, Vol. 3 No. 1

\section{Pendahuluan}

\subsection{Analisis Situasi}

Kabupaten Kutai Kartanegara adalah kabupaten yang berada di Provinsi Kalimantan Timur, kabupaten yang memiliki luas wilayah 27.263,10 $\mathrm{km}^{2}$ dan luas perairan sekitar 4.097 $\mathrm{km}^{2}$ ini terdiri dari 18 kecamatan dan lebih dari 200 desa. Wilayah sebagian besar bergelombang dan berbukit dengan kelerengan landai sampai curam.

Daerah dengan kemiringan datar sampai landai terdapat di beberapa bagian, yaitu wilayah pantai dan daerah aliran sungai Mahakam. Pada wilayah pedalaman dan perbatasan pada umumnya merupakan kawasan pegunungan dengan ketinggian antara 500 hingga $2.000 \mathrm{~m}$ di atas permukaan laut.

Kabupaten Kutai Kartanegara memiliki beberapa lokasi wisata alam, budaya dan pendidikan, ada sekitar 18 obyek wisata antara lain, pantai pangempang di Muara Badak, bukit bangkirai di Samboja, pantai tanah merah di Samboja, danau Semayang di Kota Bangun, danau murung di Kota Bangun, waduk panji sukarame di Tenggarong, pulau kumala di Tenggarong, taman rekreasi tepian mahakam jembatan kartanegara di Tenggarong. Wisata budaya terdiri dari desa sungai bawang di Muara Badak (Kehidupan Suku Dayak), museum mulawarman di Tenggarong (peninggalan Kesultanan Kutai Kartanegara), kedaton kutai kartanegara di Tenggarong (istana baru Sultan Kutai Kartanegara), desa pondok labu di Tenggarong (kehidupan suku dayak), desa lekaq kidau di Sebulu, lamin suku dayak di Tabang (kehidupan suku dayak), dusun berubus di Muara Kaman (situs kerajaan tertua di Indonesia) dan wisata pendidikan yaitu planetarium jagad raya di Tenggarong, museum kayu tuah himba di Tenggarong, museum perjuangan merah putih di Sanga-sanga.

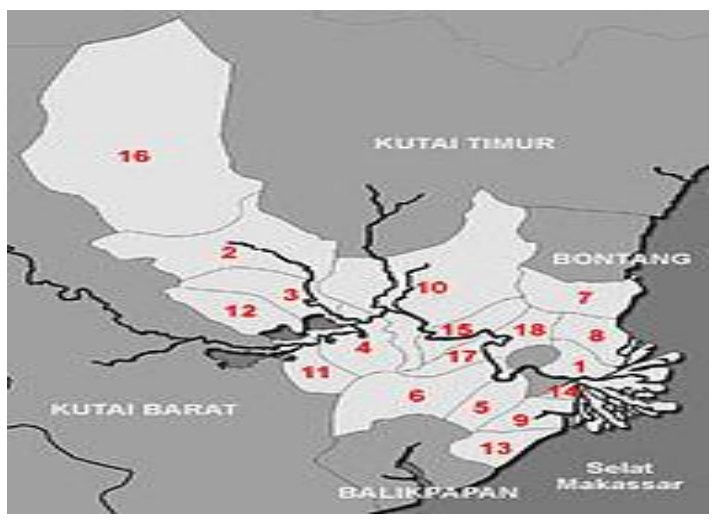
1. Anggana
2. Kembang Janggut
3. Kenohan
4. Kota Bangun
5. Loa Janan
6. Loa Kulu
7. Marang Kayu
8. Muara Badak
10. Muara Kaman
11. Muara Muntai
12. Muara Wis
13. Samboja
14. Sanga-Sanga
15. Sebulu
16. Tabang
17. Tenggarong
9. Muara Jawa
18. Tenggarong
Seberang

Gambar 1. Denah lokasi Kabupaten Kutai Kartanegara

Loa Kulu merupakan sebuah kecamatan yang terletak di wilayah tengah Kabupaten Kutai Kartanegara yang berbatasan langsung dengan Kecamatan Tenggarong dan Kecamatan Loa Janan, Kecamatan Loa Kulu memiliki luas wilayah mencapai $1.405,7 \mathrm{~km}^{2}$ yang dibagi dalam 15 desa.

Desa Loh Sumber adalah salah satu desa yang masuk dalam wilayah Kecamatan Loa Kulu, desa yang memiliki suasana pedesaan yang asri dan sejuk dimana banyak terdapat persawahan, perkebunan dan pohon-pohon besar yang teduh, aktifitas masyarakat yang mayoritas bertani dan berkebun ini masih aktif dalam sosial seperti gotong royong kebersihan lingkungan. Akses menuju desa ini sangat mudah karena sudah memiliki jalur semenisasi dan tidak jauh dari pusat kota Tenggarong yang bisa ditempuh sekitar $9,8 \mathrm{~km}$ atau 20 menit perjalanan dan pusat kota Samarinda yang bisa ditempuh sekitar $17 \mathrm{~km}$ atau 1 jam perjalanan. Desa Loh Sumber memiliki 


\section{(A) ABDIMAS}

https://journal.uwgm.ac.id/index.php/abdimasmahakam/index

E-ISSN: 2549-5755

Januari 2019, Vol. 3 No. 1

2 produksi lokal yaitu tempe daun dan kerupuk, masing-masing produksi terdiri dari 4 lokasi UMKM tempe dan terdapat 1 lokasi UMKM kerupuk.
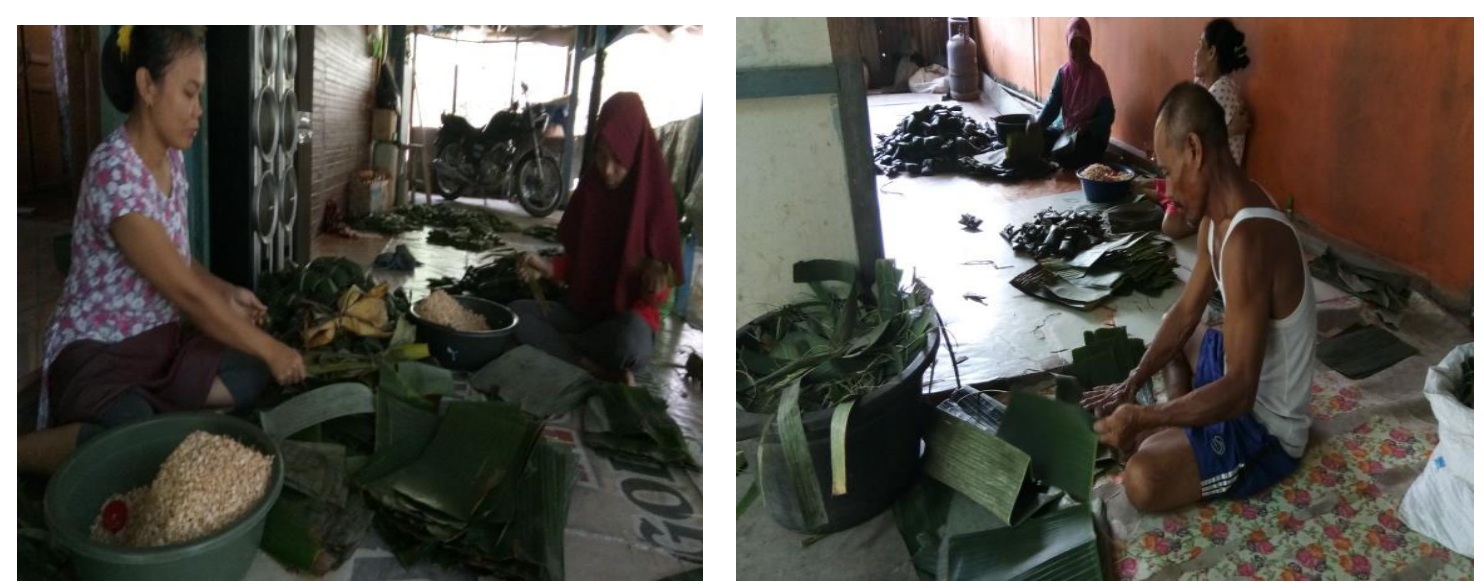

Gambar 2. Proses pembungkusan tempe

Dalam proses pembuatan tempe kendala yang dihadapi oleh pelaku usaha yang paling mendasar ialah rendahnya produksi tempe daun yang dihasilkan tidak sesuai dengan tingginya permintaan masyarakat akan tempe.

Oleh karena itu kegiatan pengabdian kepada masyarakat yang akan dilaksanakan melalui program Ipteks Kewirausahaan untuk Masyarakat (IKuM), yaitu :

- Menerapkan alat modern berupa mesin pengupas kulit kedelai guna meningkatkan hasil produksi dan penambahan alat-alat pendukung lainnya seperti ember, baskom, keranjang dan lainnya.

- Melaksanakan sosialisasi dan pelatihan dalam penggunaan alat penggiling kedelai

\subsection{Permasalahan Mitra}

Studi pendahuluan yang dilakukan oleh tim pengusul dapat diidentifikasi permasalahan sebagai berikut :

a. Rendahnya hasil produksi tempe daun oleh pelaku usaha.

b. Tingginya permintaan masyakarakat dalam mengkonsumsi tempe daun.

\subsection{Identifikasi dan Perumusan Masalah}

Tempe tradisional yang menggunakan kemasan daun pisang memiliki keunggulan dari segi kesehatan dan daya tahan sehingga meningkatkan kepercayaan masyarakat dalam mengkonsumsinya namun tingginya permintaan masyarakat tidak dapat sepenuhnya dipenuhi oleh pelaku usaha karena rendahnya jumlah produksi yang dihasilkan. Rendahnya hasil produksi tempe tersebut dikarenakan masih menggunakan metode tradisional dalam pengolahan tempe, seperti mengupas kedelai dengan cara manual (menginjak-injak), cara tersebut akan berdampak pada lambatnya proses pemisahan kulit kedelai dan hasil kerja yang kurang maksimal, sehingga dibutuhkan pekerja/karyawan yang lebih banyak pada proses produksi ini yang berdampak pada menurunnya profit produsen. Untuk mengoptimalkan hasil produksi tempe dan menekan biaya pengeluaran berupa gaji pekerja maka perlu menerapkan sebuah teknologi modern berupa mesin pengupas kulit kedelai. diharapkan dapat meningkatkan kepercayaan masyarakat dalam mengkonsumsi tempe daun. Masalah yang dihadapi produsen tempe daun ini pada dasarnya adalah belum memiliki alat modern yang akan meningkatkan jumlah produksi tempe dalam rangka memenuhi permintaan masyarakat yang tinggi. 


\section{(A) ABDAIMAS}

https://journal.uwgm.ac.id/index.php/abdimasmahakam/index

E-ISSN: 2549-5755

Januari 2019, Vol. 3 No. 1

\subsection{Tujuan Kegiatan}

Kegiatan Iptek Kewirausahaan untuk Masyarakat (IKuM) ini bertujuan agar pelaku usaha (produsen) tempe daun yang ada di Desa Loh Sumber dapat meningkatkan jumlah produksi tempe dan memenuhi permintaan masyarakat, kemudian berdampak pada profit produsen tempe daun.

\subsection{Manfaat Kegiatan}

Kebermanfaatan dalam kegiatan ini ialah meningkatkan kesejahteraan masyarakat pelaku usaha dan terpenuhinya kebutuhan konsumen akan tempe yang sehat dan nikmat.

\section{Metode}

Dalam proses pembuatan tempe terdapat beberapa cara yang dapat dilakukan, yaitu bisa menggunakan cara tradisional ataupun modern. Berikut penjelasannya:

a. Tradisional

1) Cuci bersih semua peralatan terlebih dahulu. Keringkan.

2) Cuci bersih kacang kedelai.

3) Rendamlah kacang kedelai kurang lebih selama 13-18 jam.

4) Jika sudah lunak, kelupas kulitnya.

5) Bilas menggunakan air.

6) Rebus kembali biji kedelai yang sudah dibilas air tadi.

7) Tiriskan pada tampah. Kipasi menggunakan kipas angin hingga tidak terlalu panas.

8) Masukkan ragi tempe ke biji kedelai secara merata, aduk rata.

9) Masukkan biji kedelai yang sudah diberi ragi pada daun pisang atau kantong plastik. Untuk tebal tipisnya sesuai dengan selera anda.

10) Untuk mendapatkan tempe yang baik, waktu yang dibutuhkan untuk proses fermentasi adalah 2 hari dengan suhu kamar. Usahakan kacang kedelai anda sudah tertutupi jamurnya.

b. Modern

Dalam proses produksi modern tidak berbeda tahapannya dari tradisional namun dibedakan dengan alat yang digunakan.

1) Cuci bersih semua peralatan terlebih dahulu. Lalu keringkan dengan alat pengering.

2) Cuci bersih kacang kedelai.

3) Rendamlah kacang kedelai kurang lebih selama 13-18 jam.

4) Jika sudah lunak, kelupas kulitnya dengan menggunakan alat pengupas kedelai.

5) Bilas menggunakan air.

6) Rebus kembali biji kedelai yang sudah dibilas air tadi.

7) Tiriskan pada tampah. Kipasi menggunakan kipas angin hingga tidak terlalu panas.

8) Masukkan ragi tempe ke biji kedelai secara merata, aduk rata.

9) Masukkan biji kedelai yang sudah diberi ragi pada daun pisang atau kantong plastik. Untuk tebal tipisnya sesuai dengan selera anda. (bisa menggunakan alat pengemas kemasan)

10) Untuk mendapatkan tempe yang baik, waktu yang dibutuhkan untuk proses fermentasi adalah 2 hari dengan suhu kamar. Usahakan kacang kedelai anda sudah tertutupi jamurnya. 


\section{(A) ABDIMAS}

https://journal.uwgm.ac.id/index.php/abdimasmahakam/index

E-ISSN: 2549-5755

Januari 2019, Vol. 3 No. 1

\section{Hasil dan Pembahasan}

Kegiatan Iptek Kewirausahaan untuk Masyarakat (IKuM) ini merupakan suatu kegiatan pengabdian pada masyarakat yang dijalani tim pengabdi dan merupakan bagian dari amanat Tri Dharma Perguruan Tinggi, pada kesempatan ini pengabdi melaksanakan kegiatan dalam rangka meningkatkan produksi tempe daun yang ada di Kecamatan Loa Kulu. Pada proses pelaksanannya pengabdi memberikan pendampingan agar pelaku usaha dapat meningkatkan produksi tempe dengan melihat beberapa aspek seperti alat dan kebutuhan pelengkap lainnya untuk menunjang peningkatan produksi tempe daun.

\section{A. Kegiatan}

Dengan melihat pada uraian diatas, maka dalam menjalankan usaha produksi tempe terdapat beberapa hal yang harus diperhatikan dari alat dan bahan lainnya. Tim pengabdi berupaya memberikan arahan dan solusi kepada pelaku usaha agar meningkatkan produksi tempe tersebut yang dijelaskan pada uraian berikut.

\section{Sosialisasi}

Dalam usaha meningkatkan produksi tempe, pengabdi berusaha mensosialisasikan pentingnya alat modern agar terpenuhinya produksi tempe yang lebih besar, karena melihat kondisi saat itu yang belum menggunakan alat modern dalam pengupasan kulit kedelai, kemudian memberikan pelatihan singkat dalam pengoperasian alat pengupas kulit kedelai, karena pelaku usaha masih belum bisa dalam penggunaan alat tersebut.

\section{Pengadaan Alat}

Setelah melihat dari hasil survey yang dilaksanakan sebelumnya dapat diketahui permasalahan dan kendala yang dihadapi oleh pelaku usaha dalam meningkatkan hasil produksi tempe ialah belum menggunakan alat pengupas kulit kedelai yang modern, maka solusi yang dapat diberikan oleh pengabdi ialah pengadaan alat pengupas kulit kedelai yang modern dan efisien sehingga tidak membutuhkan tenaga kerja yang lebih banyak kemudian dapat mengurangi modal yang dikeluarkan untuk membayar tenaga kerja, alat lainnya yang perlu dalam proses pengolahan ialah baskom besar untuk menampung kedelai yang direndam (pembersihan), lalu keranjang sebagai penyaring kedelai yang telah direndam.

\section{Pelatihan}

Setelah memberikan sosisalisasi dan pengadaan alat, selanjutnya yang perlu dilakukan ialah memberikan sebuah pelatihan kepada pelaku usaha agar dapat memahami proses dalam pengoperasian alat pengupas kulit kedelai.

\begin{tabular}{|l|l|l|}
\hline \multicolumn{1}{|c|}{ Pelaksanaan } & \multicolumn{1}{|c|}{ Produksi @hari } & $\begin{array}{c}\text { Bahan Dasar Kedelai } \\
@ \text { hari }\end{array}$ \\
\hline Sebelum Menggunakan Alat & 2500 bungkus tempe & $25 \mathrm{~kg}$ \\
\hline Sesudah Menggunakan Alat & 3500 bungkus tempe & $35 \mathrm{~kg}$ \\
\hline
\end{tabular}

Table 1. Perbandingan Hasil Produksi Tempe Sebelum dan Sesudah Menggunakan Alat Pengupas Kulit Kedelai 


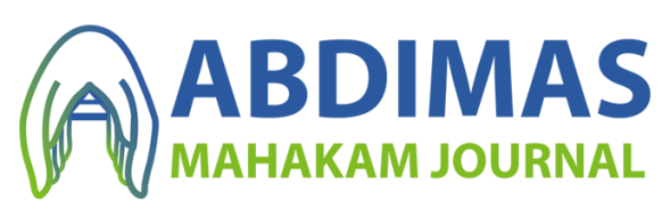

https://journal.uwgm.ac.id/index.php/abdimasmahakam/index

E-ISSN: 2549-5755

Januari 2019, Vol. 3 No. 1

\section{Simpulan dan rekomendasi}

Dari hasil kegiatan pengabdian pada masyarakat tersebut dapat diambil kesimpulan sebagai berikut :

1. Penggunaan alat modern pengupas kulit kedelai dapat meningkatkan hasil produksi tempe dan menekan biaya tenaga pekerja karena dapat dikerjakan dengan alat serta mempersingkat waktu produksi.

2. Bagi pelaku usaha tempe lainnya tentu dapat menggunakan cara yang sama yaitu menggunakan alat pengupas kulit kedelai yang modern. 


\section{(A) ABDAIMAS}

https://journal.uwgm.ac.id/index.php/abdimasmahakam/index

E-ISSN: 2549-5755

Januari 2019, Vol. 3 No. 1

\section{Daftar Pustaka}

Inestha Naldi. (2014). Strategi Pemasaran Rumah Tempe di Bogor. Skripsi. Institut Pertanian Bogor

Lieli suharti,Like Sugiono, Yenny Purwati. Model adopsi inovasi teknologi pada UMKM tempe: studi pada pengrajin tempe anggota KOPTI di kotamadya salatiga dan kabupaten boyolali, jawa tengah

Rahayu Astuti. (2014). Komposisi zat gizi tempe yang difortifikasi zat besi dan vitamin A pada tempe mentah dan matang. Agritech. Vol.34, No.2.

Sunyoto, Sujiantoro, Yosta Yoserizal. Penguatan Usaha Melalui Aplikasi Teknologi Tepat Guna bagi Kelompok Pengrajin Tempe. Peduli - Jurnal Ilmiah Pengabdian Masyarakat. Vol 1 No 2. 